\title{
Seeking our shared wisdom: a framework for understanding knowledge coproduction and coproductive capacities
}

\author{
H. Z. Schuttenberg ${ }^{1,2}$ and Heidi K. Guth ${ }^{3}$
}

\begin{abstract}
The widespread disconnect between scientific projections of climate change and the implementation of responsive management actions has escalated calls for knowledge production processes able to exercise a stronger voice in decision making. Recently, the concept of coproduction has been championed as a potential answer. The term 'knowledge coproduction' is used loosely in the literature to describe an inclusive, iterative approach to creating new information; it is distinguished by its focus on facilitating interactions between stakeholders to develop an integrated or transformational understanding of a sustainability problem. Whether a coproduction process is successful in this integration of science and policy depends on a range of capabilities that should be understood as 'coproductive capacities.' We draw on the literature from sustainability science to propose a conceptual framework that specifies the sequential goals of knowledge coproduction and potential sources of coproductive capacity. We apply this framework to examine our experience facilitating the coproduction of a climate change action plan for Papahānaumokuākea Marine National Monument and World Heritage Site. This framework offers a structure for systematically investigating the capacities, mechanisms, and dynamics of knowledge coproduction and for guiding the design of coproduction processes.
\end{abstract}

Key Words: climate change; coproduction; coral reef management; governance; traditional ecological knowledge

\section{INTRODUCTION}

Compelling scientific evidence about the likely impacts of climate change on social-ecological systems (SES) has generally not been met with proportionate management or policy responses capable of maintaining the sustainability of these systems (Hansen et al. 2010, Peters et al. 2013). This reality provides renewed urgency to long-debated questions about what kind of knowledge or knowledge-generation processes can sway decision making largely dominated by political concerns (Weiss 1973, 1976, Stone 2002), and what processes can effectively facilitate the interdisciplinary understanding needed to respond to complex social-ecological problems (Christie 2011, Pretty 2011, Holm et al. 2012, Pahl-Wostl et al. 2012). Recently, the concept of coproduction has been championed as a potential answer (Mauser et al. 2013, van Kerkhoff and Lebel 2015). Coproduction generally refers to a collaborative and dynamic knowledgegeneration process that more fully grounds scientific understanding in a relevant social, cultural, and political context. It has an explicit intention to create usable knowledge that influences decision making (Mitchell et al. 2006). Whether a coproduction process is successful in integrating science and policy depends on a range of capabilities and competencies, which van Kerkhoff and Lebel (2015) argue should be identified and understood as a distinct set of variables known as 'coproductive capacities.'

We present an inductive investigation of a knowledge coproduction project implemented in the Hawaiian Islands, as a contribution toward van Kerkhoff and Lebel's effort to explore and describe coproductive capacity. Drawing on the literature from sustainability science, we propose a conceptual framework that specifies the sequential goals of knowledge coproduction and the potential sources of coproductive capacity. We apply this framework to examine our experience facilitating the coproduction of a climate change action plan $\left(\mathrm{C}_{2} \mathrm{AP}\right)$ for
Papahānaumokuākea Marine National Monument (PMNM) and World Heritage Site. This work provides an empirical example of the supports and barriers to knowledge coproduction, while illustrating the nature and nuances of coproductive capacity.

A conceptual framework for investigating coproductive capacity The term 'knowledge coproduction' is used loosely in the literature to describe an inclusive, iterative approach to creating new information; it is distinguished by its focus on facilitating interactions between stakeholders to develop an integrated or transformational understanding of a sustainability problem (Blackstock et al. 2007, Pohl 2008, Lang et al. 2012). Knowledge coproduction is described as both a governance strategy (Armitage et al. 2012, Bremer and Glavovic 2013) and a research method. In the latter case, it is often defined referentially, as transdisciplinary research (Future Earth transition team 2012) or interactive research for sustainability science (Lemos and Morehouse 2005). As a research paradigm, it takes the position that all knowledge systems implicitly reflect a system of value judgments, including positivist science (Walter et al. 2007). From this perspective, knowledge coproduction sees the boundary between science and policy, or between facts and values, as porous or even artificial (Pohl 2008).

We draw on recent literature from sustainability science to propose an explicit conceptual framework for knowledge coproduction as the lens for our inquiry into coproductive capacity. We first focus on the theory of change that underpins knowledge coproduction by identifying the immediate, intermediate, and ultimate goals of knowledge coproduction. We then consider what capabilities are needed to achieve these outcomes and where these capabilities might be found. Through this process, we highlight three key questions about knowledge coproduction that guided our research:

${ }^{1}$ School of Biological Sciences and Centre for Sustainable International Development, University of Aberdeen, UK, ${ }^{2}$ currently with the United States Agency for International Development (USAID), E3 Bureau, Office of Forestry and Biodiversity, ${ }^{3}$ Kai Ho'oulu LLLC and Polynesian Voyaging Society 
Fig. 1. Conceptual framework that specifies the sequential goals of knowledge coproduction (identified as O1-O3) and potential sources of coproductive capacity (C1-C3).

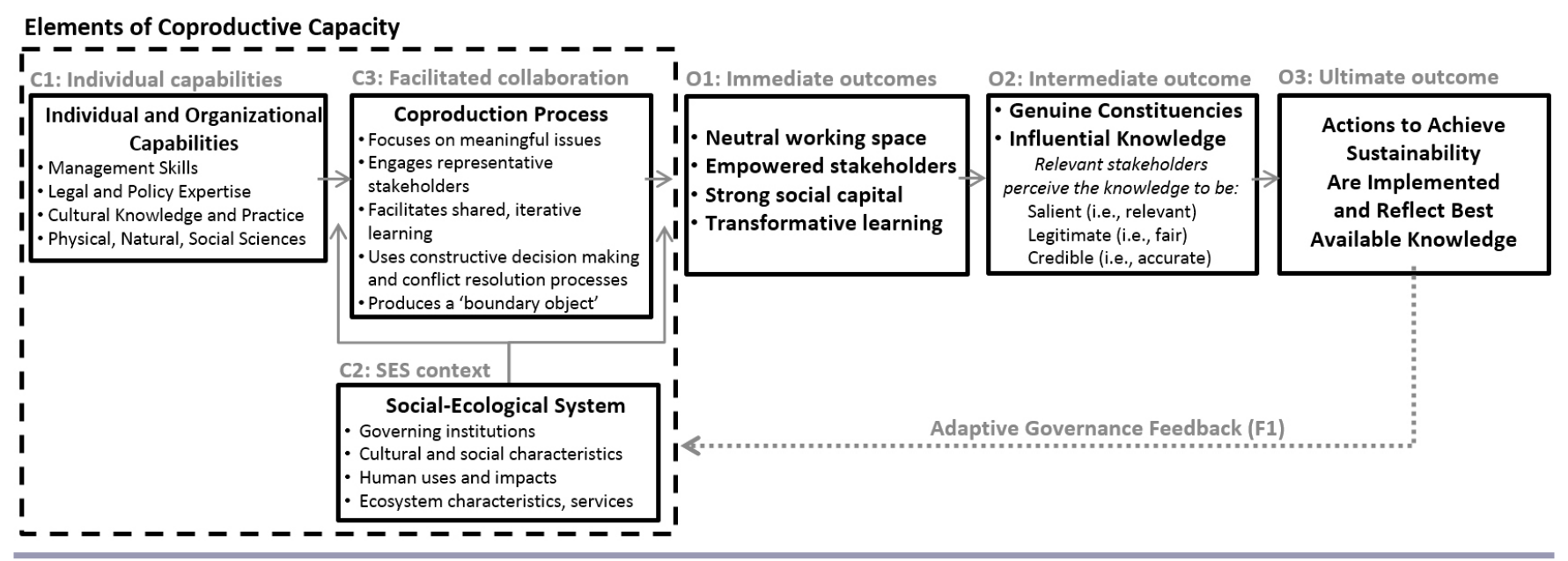

1. What are the relative contributions of different sources of coproductive capacity toward achieving the goals of knowledge coproduction?

2. To what extent should different types of knowledge be integrated or transformed into new knowledge as part of a coproduction process?

3. Can the facilitated process used to coproduce knowledge overcome institutional barriers found within the broader social-ecological context to help solve complex sustainability problems?

Theory of change for knowledge coproduction

Knowledge coproduction may be best understood as a category of participatory research and collaborative governance approaches that broadly follow the theory of change presented in Figure 1 (note $\mathrm{O}$ and $\mathrm{C}$ labels). The ultimate goal (O3) of these approaches is to catalyze decisions and actions that reflect the best available knowledge as a response to complex sustainability problems (Cash et al. 2003, Crona and Parker 2012, Future Earth transition team 2012, Mauser et al. 2013). To achieve this ultimate goal, knowledge coproduction focuses on the 'process' of knowledge creation as much as on its resultant products (Walter et al. 2007). It theorizes that the ultimate goal (O3) will be achieved when there is a shared understanding of the problem (Blackstock et al. 2007) and a genuine constituency (Lang et al. 2012) for responding to it. It further hypothesizes that these intermediate outcomes (O2) will be achieved if the knowledge coproduction process leads to a set of immediate outcomes (O1): empowered stakeholders (Lang et al. 2012), high social capital (Armitage et al. 2012); an equitable, accountable working space (Walter et al. 2007); and transformative learning (Blackstock et al. 2007). Essentially, knowledge coproduction trusts the ability of stakeholder teams to effectively solve complex problems when there is appropriate representation, capacity, trust, and commitment to learning.

The logic or mechanism linking these immediate $(\mathrm{O} 1)$ and intermediate $(\mathrm{O} 2)$ outcomes is suggested by the prevalence of two themes in the coproduction literature: interaction and transformation. Iterative stakeholder interactions, which facilitate a shift from disparate, self-focused perspectives of a problem into a holistic, collective framing, are central to knowledge coproduction (Blackstock et al. 2007). Using stakeholder interactions as a primary mechanism for knowledge creation implicitly involves issues and questions related to power, including: which stakeholders are represented; how does stakeholder capacity vary in terms of time, information, resources, and social connections; and how are stakeholder voices supported or suppressed by institutional laws and norms in the broader social context (Walter et al. 2007, Armitage et al. 2012, Bremer and Glavovic 2013). Coproduction scholars are clear that for this theory of change to succeed, the coproduction process (C3) must enable, "a tangible cooperation on an equal footing" (Walter et al. 2007:328). Even if there are power imbalances in the broader social context $(\mathrm{C} 2)$, the coproduction process needs to create an oasis in which stakeholders are given an equal voice so that trust, creativity, and shared understanding can develop.

Transformation or an integration of diverse knowledge systems is a second dominant theme in the coproduction literature. Pohl (2008) argues that simply reorganizing knowledge from different disciplines or cultures to inform a real-world problem is inadequate to be considered coproduction. For Pohl, coproduction occurs when the interactions between actors serve to minimize differences in their cultural backgrounds and to emphasize the collective nature of the endeavor. Blackstock et al. (2007:726) add that what is needed from this ongoing collective dialogue is a "transformation in understanding and practice." In our model, we emphasize an immediate goal of facilitating transformational learning $(\mathrm{O} 1)$, but intentionally do not propose a goal of producing transformation knowledge as an intermediate coproduction outcome $(\mathrm{O} 2)$. The literature on integrating Indigenous knowledge and Western science articulates both significant risks and compelling reasons for integration (Berkes et al. 2006, Bohensky and Maru 2011). Noting these issues, we pose a question about what level of integration is appropriate for successful knowledge coproduction. We propose that coproduction needs to enable a transformation in thinking that 
allows stakeholders to embrace ideas beyond their own disciplines and cultures and leads to new, creative solutions (O1). We suggest that the resulting knowledge $(\mathrm{O} 2)$ should be evaluated against the criteria identified by Cash et al. (2003) and Mitchell et al. (2006): that knowledge will be influential in decision making when it is perceived as salient, legitimate, and credible by key stakeholder groups. In this usage, salience means that knowledge is considered relevant and adequate to inform decision making; legitimate means that it is perceived as inclusive, fair, and unbiased; and credible means that the information is considered accurate, or "at least a better guide to how the world works than competing information" (Mitchell et al. 2006:317).

Potential sources of coproductive capacity

If these are the goals of coproduction, what are the capacities needed to achieve them and where are these capacities found? Our framework proposes three broad sources of coproductive capacity. The first source is the existing individual and organizational capacities for science, traditional knowledge, management, and governance $(\mathrm{C} 1)$. These capabilities and competencies are often considered the foundation for effective problem solving within natural resource science and governance. Their inclusion as a source of coproductive capacity reflects a hypothesis that strong abilities in these individual domains will support the coproduction of transdisciplinary or transformational knowledge (van Kerkhoff and Lebel 2015).

The second source of coproductive capacity is the broader socialecological system (SES) in which knowledge coproduction processes takes place (C2), including its biophysical, social, cultural, and institutional characteristics (Glaser et al. 2012). This context has been described as the enabling environment for capacity development (UNDP 1998). Our framework hypothesizes the SES as a set of moderating variables, which will influence the outcomes of the coproduction process.

The third source of coproductive capacity is the knowledge coproduction process itself (C3). Whereas the first two sources of coproductive capacity may be considered inherent or slowchanging characteristics of the system in which coproduction will occur, the coproduction process is the source of coproductive capacity that is easiest to influence and change. Lang et al. (2012) offered design principles for a transdisciplinary research or knowledge coproduction process, which divided the process into three phases: problem framing and team building, cocreation of solution-oriented knowledge, and integration and application of created knowledge. They noted that all three stages required constant reflection, conflict resolution, and capacity building. We distill the essential capacities for a knowledge coproduction process as the ability to: convene capable representatives from all relevant stakeholder groups (Blackstock et al. 2007); facilitate an iterative, shared learning process around a meaningful issue (Pohl 2008); establish processes for decision making and conflict resolution that are perceived as fair and constructive (Lang et al. 2012); and work toward a tangible product(s) or outcome(s), sometimes called a 'boundary object,' which requires the inclusion of knowledge from divergent stakeholder groups and provides a concrete focus for the group's work (Walter et al. 2007).

\section{METHODS AND CASE STUDY}

The purpose of this analysis is to explore and describe the concept of coproductive capacity, as proposed by van Kerkhoff and Lebel (2015).

\section{Methods}

We conducted an inductive, post-hoc analysis of a knowledge coproduction process that we helped facilitate. We reviewed qualitative data from semistructured interviews conducted with 13 key informants in the scoping phase of the project, materials produced during the knowledge coproduction, and our own participant observations. We structured our analysis around the characteristics of usable knowledge (O2, Fig. 1) identified by Cash et al. (2003) and Mitchell et al. (2006). This focus was chosen because it is too soon to determine if the coproduction process being investigated will achieve its ultimate goal and because these criteria have been used in other studies (e.g., White et al. 2010). Specifically, we investigated what factors influenced whether the three main stakeholder groups perceived the boundary object developed through the project as salient, legitimate, and credible. We then organized these factors based on their alignment with the potential sources of coproductive capacity identified in our framework.

\section{Case study}

This case study examines the coproduction of a climate change action plan $\left(\mathrm{C}_{2} \mathrm{AP}\right)$ for the Papahānaumokuākea Marine National Monument (PMNM) and World Heritage Site. Over two years, we helped facilitate a coproduction process to develop the $\mathrm{C}_{2} \mathrm{AP}$, a document that includes an analysis of the key issues and implications of climate change for PMNM and an action plan for responding to this information. This initiative was conducive to coproduction because crafting Papahānaumokuākea's response to climate change required an integration of technical information with complex legal mandates and an understanding of cultural perspectives and other social values. We describe the case study in terms of the three sources of coproductive capacity proposed in our framework: the SES context, existing stakeholder capacities, and the coproduction process.

\section{Social-ecological context}

Papahānaumokuākea Marine National Monument is one of the largest marine protected areas in the world and a unique cultural and ecological seascape (PMNM 2008a). Encompassing about $362,000 \mathrm{~km}^{2}$ northwest of the main Hawaiian Islands, it is a particularly isolated portion of the Hawaiian archipelago, which includes 10 major island, atoll, and reef areas. Native Hawaiians honor the region for its spiritual and distinctive archeological significance (Emory 2002), as well as for its presence as an ancestral environment. Papahānaumokuākea Marine National Monument also has a rich military history and a seafaring legacy (PMNM 2011), and it is recognized for its exceptionally high levels of endemism, predator dominated coral reef ecosystems, and numerous endangered species, which include marine mammals, sea turtles, and the world's largest tropical seabird rookery (Friedlander and DeMartini 2002, DeMartini and Friedlander 2004, PMNM 2008a, Friedlander et al. 2009). Although its remote location protects PMNM from most anthropogenic stressors, the area remains highly vulnerable to climate change, particularly sealevel rise and impacts to its coral reef and freshwater ecosystems (Selkoe et al. 2008, 2009).

The use and conservation of the Northwestern Hawaiian Islands (NWHI) has been managed for more than 100 years through a series of state and federal executive orders (Rauzon 2001, Shallenberger 2006). On June 15, 2006, George W. Bush signed 
Presidential Proclamation 8031, designating the area as a National Monument and providing the highest level of environmental protection available in the U.S. (United States Government 2006a). All extractive use is prohibited within the monument's boundaries, and permits are required for all activities, including management interventions, cultural practices, research, and tourism (United States Government 2006b, PMNM $2008 b$ ). Designation established an intergovernmental comanagement arrangement for the monument, which is implemented through the Monument Management Board (MMB), consisting of the State of Hawaii, two federal agencies, and the Office of Hawaiian Affairs (PMNM 2008b, Kittinger et al. 2011). The current management arrangements continue a tradition of active stakeholder engagement by hosting a number of thematic working groups and consulting on significant management and policy documents through the Federal Register Notice and the State of Hawai'i's Board of Land and Natural Resources. To guide their work, the MMB developed and adopted a 370-page management plan (PMNM 2008b:1) aimed at achieving a vision to "forever protect and perpetuate ecosystem health and diversity and Native Hawaiian cultural significance of Papahānaumokuākea."

\section{Stakeholder capacities}

The coproduction process engaged three main groups of actors: Western scientists, Native Hawaiian cultural practitioners, and PMNM's government managers. All three stakeholder groups brought significant capacity to this endeavor. A series of largescale, policy-driven research initiatives originating in the 1970 s has bolstered scientific capacity and infrastructure for research in the NWHI (Grigg 2006). As a result of these investments and ongoing monitoring by PMNM and its partners, many of the government and academic scientists involved in developing the $\mathrm{C}_{2} \mathrm{AP}$ have decades of experience conducting research in the NWHI, and several are world leaders in their fields. Similarly, Native Hawaiian contributions to the $\mathrm{C}_{2}$ AP's credibility were also grounded in the ability to directly experience Papahānaumokuākea. At the experts' workshop, most Native Hawaiian cultural practitioners listed their previous visits to PMNM as part of the basis for their presentations. The capacity to integrate Native Hawaiian perspectives into the $\mathrm{C}_{2}$ AP's coproduction process was also supported by a resurgent movement to reconnect with an enduring body of Hawaiian cultural and ecological knowledge that is held within chants, stories, and songs (PMNM 2008a). In reclaiming their ancestral connections, cultural practitioners are accessing a body of experiential knowledge that reaches back over a millennium (Kame'eleihiwa 2009).

Knowledge coproduction process

The $\mathrm{C}_{2} \mathrm{AP}$ coproduction initiative aimed to identify how climate change should be integrated into the PMNM's management. The immediate catalyst for the initiative was a commitment by one of PMNM's comanagers, NOAA's Office of National Marine Sanctuaries, to participate in a nation-wide 'Climate-Smart Sanctuary' program (NOAA 2010). To meet this commitment, PMNM's Sanctuaries Office supported a dedicated facilitator and the meeting costs associated with the process. The coproduction effort proceeded through seven phases (Fig. 2). The first two phases established the coproduction process. The third phase focused on planning and implementing an experts' workshop to develop the $\mathrm{C}_{2} \mathrm{AP}$ content, which was implemented in the fourth phase. During the fifth phase, a special session of the MMB refined draft content for the $\mathrm{C}_{2} \mathrm{AP}$. In the sixth phase, about 75 stakeholders reviewed and revised the draft $\mathrm{C}_{2} \mathrm{AP}$ during a structured 1-day workshop. The final draft $\mathrm{C}_{2} \mathrm{AP}$ will next be considered for formal adoption at an MMB meeting.

\section{RESULTS}

Table 1 summarizes the factors we identified as supports and barriers to actors' perceptions of the $\mathrm{C}_{2}$ AP's salience, legitimacy, and credibility, and the supports and barriers to the integration of different knowledge types. Table 2 groups the supportive factors by their sources of coproductive capacity.

\section{Salience}

We observed four institutional supports for establishing the $\mathrm{C}_{2}$ AP's salience among key stakeholder groups: (1) the presence of broader-scale policy mandates and budgets; (2) recent trainings, which fostered capacity and established a local frame for global issues; (3) the project's orientation around identifying and supporting key management decisions; and (4) established investment in and recognition of PMNM as a special place. The main barrier we observed in establishing the $\mathrm{C}_{2}$ AP's salience was a perception that climate change impacts on PMNM are distant and therefore of comparatively lower priority. Among PMNM's comanagers this distance was mainly temporal; scoping interviews with government staff found widespread acceptance that climate change posed significant threats to PMNM, but a concurrent belief that these changes were not imminent. Among Native Hawaiians, who participated in state-wide focus groups to establish PMNM's Native Hawaiian Research Plan, climate change was not identified as a key issue, with priorities instead focusing on access to PMNM's resources to maintain ancestral connections and increasing Native Hawaiian management capacity (K. Kuoha, personal communication). A perception of the spatial distance between remote PMNM and the populated main Hawaiian Islands is also a barrier to establishing widespread support for a focus on climate change impacts within the monument. Representatives from all stakeholder groups indicated that the $\mathrm{C}_{2}$ AP's salience would be enhanced to the extent it facilitated comparisons between the NWHI and the main Hawaiian Islands, in the process increasing its relevance to those living in the Islands.

\section{Legitimacy}

We identified two institutional supports for establishing the legitimacy of the $\mathrm{C}_{2} \mathrm{AP}$ among key stakeholder groups: (1) legal recognition of existing institutional arrangements, and (2) characteristics of the coproduction process. The leading role played by PMNM's MMB helped confer legitimacy to the $\mathrm{C}_{2} \mathrm{AP}$ through its clear legal authority and its pre-existing formal and informal relationships with other stakeholder groups. The emphasis given to representation, transparency, and accountability in implementing the coproduction process was a second institutional support for legitimacy. For example, collaboratively developing an 'options paper' (H. Z. Schuttenberg and D. Polhemus, unpublished report) prior to deliberating the $\mathrm{C}_{2} \mathrm{AP}$ 's content provided a transparent mechanism for eliciting and documenting the range of perspectives and issues being raised by stakeholders and the peer-reviewed literature.

The main barrier we observed to establishing the $\mathrm{C}_{2}$ AP's legitimacy was an incongruence in the formal and informal 
Fig. 2. The coproduction process for developing Papahānaumokuākea Marine National Monument's (PMNM) Climate Change Action Plan.

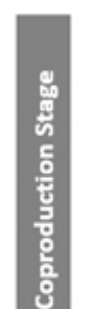

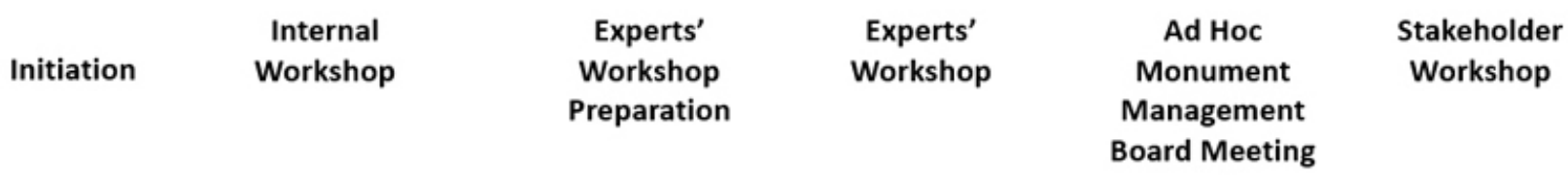

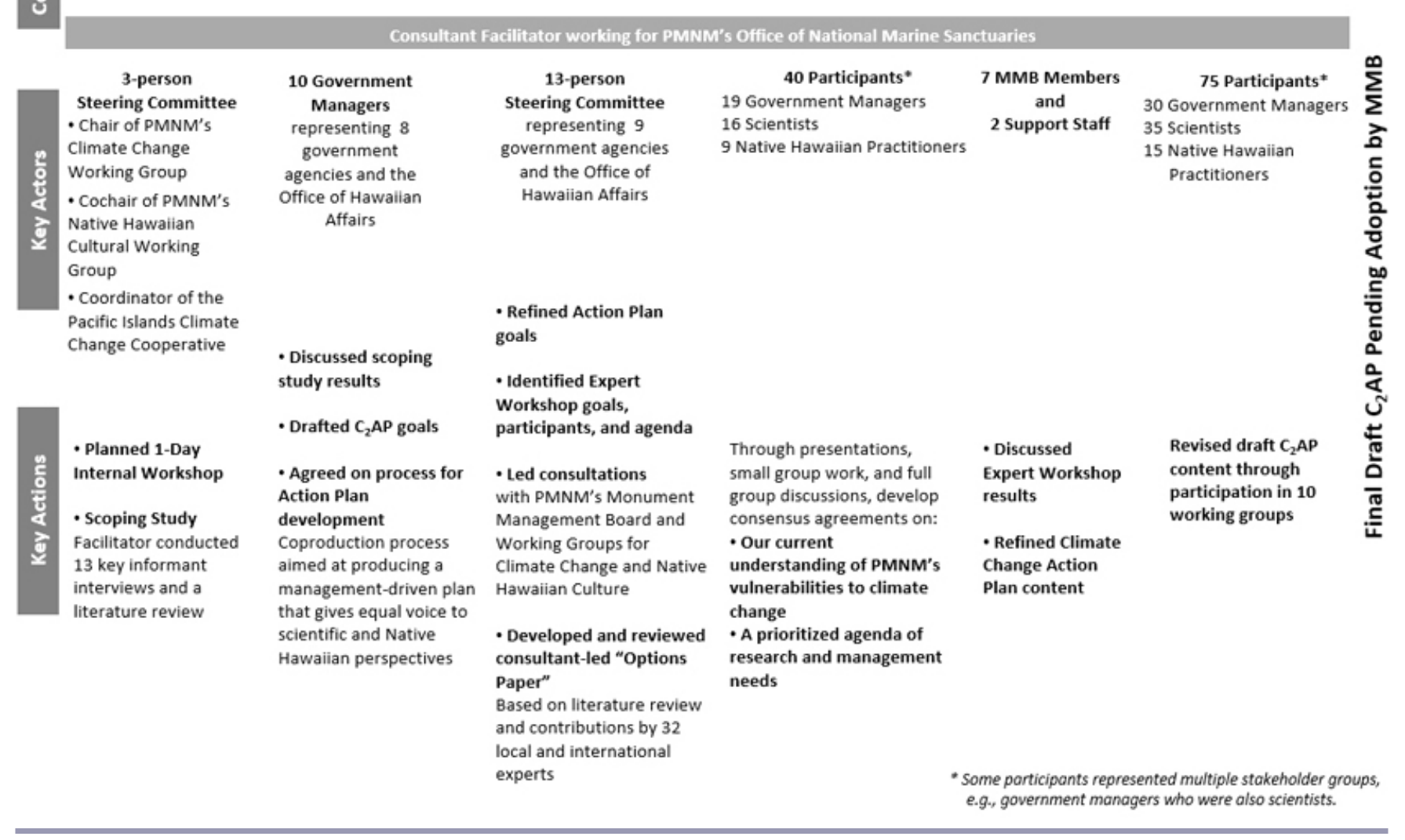

support given to Native Hawaiian perspectives by the broader SES; awareness of this disparity influenced stakeholder choices about engagement during the $\mathrm{C}_{2} \mathrm{AP}$ 's coproduction (see Discussion). There are publicly recognized policies and de facto processes that value Native Hawaiian perspectives in making management decisions for PMNM. The most visible of these are PMNM's world heritage designation for nature and culture; an active Native Hawaiian working group, which advises the MMB; and inclusion of Native Hawaiian perspectives in the PMNM's management plan. However, these policy-oriented mechanisms are not reinforced by the formal mechanisms that govern PMNM. Six of the seven positions on PMNM's Monument Management Board are held by government representatives, whom at times have been articulate and influential Native Hawaiians; one is a dedicated representative of Native Hawaiian perspectives. Thus representation of Native Hawaiian perspectives in PMNM's main decision-making forum is possible, but not consistent. Similarly, guiding environmental laws, e.g., the Endangered Species Act (1973, as amended) and the Marine Mammal Protection Act
(1972, as amended), provide very specific ecological protections and weaker mechanisms for incorporating cultural perspectives into decision making. The result is uncertainty that Native Hawaiian perspectives will be given equal weight with Western management priorities, and a perception that funding linked to these legal mandates is preferentially invested in Western science, rather than in traditional knowledge or in transdisciplinary research that aims to integrate both perspectives. We observed that the provisions created to provide equal representation within the coproduction process could not eliminate concerns about power disparities influencing the $\mathrm{C}_{2} \mathrm{AP}$ 's implementation, and that this concern influenced stakeholder engagement in the coproduction process and the way information was included in the resulting products.

\section{Credibility}

Perceptions of the $\mathrm{C}_{2}$ AP's credibility were mainly supported by the reputations and capacity of the stakeholders involved in its development. The coproduction process provided secondary support by facilitating an iterative learning process. This process 
Table 1. Factors that supported or impeded efforts to achieve salience, legitimacy, and credibility among and between the three actor groups. PMNM = Papahānaumokuākea Marine National Monument.

\begin{tabular}{|c|c|c|c|c|c|}
\hline \multicolumn{2}{|c|}{ Salient } & \multicolumn{2}{|c|}{ Legitimate } & \multicolumn{2}{|c|}{ Credible } \\
\hline \multicolumn{2}{|c|}{$\begin{array}{l}\text { Actor groups believe the issues addressed by the } \\
\qquad \mathrm{C}_{2} \mathrm{AP} \text { are important. }\end{array}$} & \multicolumn{2}{|c|}{$\begin{array}{c}\text { Actor groups believe the } \mathrm{C}_{2} \mathrm{AP} \text { was developed } \\
\text { through a fair process. }\end{array}$} & \multicolumn{2}{|c|}{$\begin{array}{l}\text { Actor groups believe the content of the } \mathrm{C}_{2} \mathrm{AP} \text { is } \\
\text { accurate. }\end{array}$} \\
\hline Support & Barrier & Support & Barrier & Support & Barrier \\
\hline $\begin{array}{l}\text { Western Scientists } \\
\text { Climate change is } \\
\text { viewed as a relevant } \\
\text { and interesting } \\
\text { scientific focus with } \\
\text { new funding } \\
\text { opportunities. }\end{array}$ & & $\begin{array}{l}\text { Coproduction process } \\
\text { developed an "options } \\
\text { paper" based on } \\
\text { inclusive scientific } \\
\text { input. }\end{array}$ & $\begin{array}{l}\mathrm{C}_{2} \mathrm{AP} \text { has not yet been } \\
\text { peer-reviewed. }\end{array}$ & $\begin{array}{l}\text { A few studies in } \\
\text { PMNM, many studies } \\
\text { from elsewhere, and } \\
\text { accepted ecological } \\
\text { principles supported } \\
\text { the } \mathrm{C}_{2} \text { AP's credibility } \\
\text { for identifying key } \\
\text { issues and a future } \\
\text { research agenda. }\end{array}$ & $\begin{array}{l}\text { A scarcity of place- } \\
\text { specific studies meant } \\
\text { the } \mathrm{C}_{2} \mathrm{AP} \text { is missing } \\
\text { detailed information } \\
\text { needed to inform } \\
\text { management decisions. }\end{array}$ \\
\hline $\begin{array}{l}\text { Native Hawaiians } \\
\text { Papahânaumokuakea } \\
\text { is culturally important } \\
\text { and there is interest in } \\
\text { what lessons could be } \\
\text { learned from PMNM } \\
\text { to inform management } \\
\text { of the Main Hawaiian } \\
\text { Islands. }\end{array}$ & $\begin{array}{l}\text { In Native Hawaiian } \\
\text { focus groups, climate } \\
\text { change was not } \\
\text { identified as a priority } \\
\text { issue for PMNM. }\end{array}$ & $\begin{array}{l}\text { Preliminary ideas were } \\
\text { vetted with PMNM's } \\
\text { Native Hawaiian } \\
\text { Cultural Working } \\
\text { Group. }\end{array}$ & $\begin{array}{l}\text { Incongruence between } \\
\text { some resource } \\
\text { protection laws and } \\
\text { Native Hawaiian } \\
\text { cultural norms. }\end{array}$ & $\begin{array}{l}\text { Traditional ecological } \\
\text { knowledge supported } \\
\text { the } \mathrm{C}_{2} \mathrm{AP} \text { 's credibility } \\
\text { for identifying key } \\
\text { issues and a future } \\
\text { research agenda. }\end{array}$ & $\begin{array}{l}\text { Logistical and financial } \\
\text { challenges of accessing } \\
\text { remote PMNM limits } \\
\text { the ability of Native } \\
\text { Hawaiians to directly } \\
\text { experience PMNM. }\end{array}$ \\
\hline $\begin{array}{l}\text { Government Managers } \\
\text { Climate change is } \\
\text { recognized as a } \\
\text { significant threat, a } \\
\text { perception reinforced } \\
\text { by recent trainings; } \\
\text { there are policy } \\
\text { mandates directing } \\
\text { managers to respond } \\
\text { and adapt to climate } \\
\text { change. }\end{array}$ & $\begin{array}{l}\text { A widely held } \\
\text { perception that climate } \\
\text { change impacts are not } \\
\text { imminent means most } \\
\text { managers are not } \\
\text { focused on making } \\
\text { immediate decisions. }\end{array}$ & $\begin{array}{l}\text { The coproduction } \\
\text { process was designed } \\
\text { by a steering } \\
\text { committee with } \\
\text { representatives from } \\
\text { each comanaging } \\
\text { agency and major } \\
\text { partners. }\end{array}$ & & $\begin{array}{l}\text { Managers selected the } \\
\text { scientists and cultural } \\
\text { practitioners involved } \\
\text { in crafting the } \mathrm{C}_{2} \mathrm{AP} \text { to } \\
\text { gain information from } \\
\text { trusted, credible } \\
\text { sources. }\end{array}$ & $\begin{array}{l}\text { Managers are aware } \\
\text { that much of the } \\
\text { existing information } \\
\text { about climate change } \\
\text { impacts on PMNM is } \\
\text { high level, and specific } \\
\text { decisions require } \\
\text { further research. }\end{array}$ \\
\hline \multicolumn{6}{|c|}{ Integration Across Actor Groups } \\
\hline $\begin{array}{l}\text { Shared interest in } \\
\text { PMNM as a special } \\
\text { place; coproduction } \\
\text { focus on management } \\
\text { decisions and } \\
\text { participation by } \\
\text { esteemed group of } \\
\text { actors. }\end{array}$ & $\begin{array}{l}\text { Perception of climate } \\
\text { change as distant } \\
\text { temporally and } \\
\text { spatially. }\end{array}$ & $\begin{array}{l}\text { The existing, formal } \\
\text { comanagement } \\
\text { structure; the } \\
\text { coproduction explicitly } \\
\text { considered } \\
\text { representation, and } \\
\text { made decisions by } \\
\text { consensus. }\end{array}$ & $\begin{array}{l}\text { Protections for Native } \\
\text { Hawaiian perspectives } \\
\text { and representation are } \\
\text { unclear; they are found } \\
\text { in policies, but less } \\
\text { clear in formal laws } \\
\text { that guide funding and } \\
\text { other decisions. }\end{array}$ & $\begin{array}{l}\text { Significant, direct } \\
\text { experiences in PMNM; } \\
\text { collaboration during } \\
\text { the coproduction and } \\
\text { historically fostered } \\
\text { trust that confers } \\
\text { credibility by proxy. }\end{array}$ & $\begin{array}{l}\text { Tension between } \\
\text { scientific and cultural } \\
\text { ways of generating } \\
\text { knowledge; complexity } \\
\text { of climate change } \\
\text { issues. }\end{array}$ \\
\hline
\end{tabular}

strengthened the document's content, and it increased the ability of different stakeholders to directly assess the strengths and weaknesses of the $\mathrm{C}_{2} \mathrm{AP}$, rather than primarily relying on the judgments of trusted others. The main barriers to perceptions of credibility we observed were the unique nature of the NWHI, the challenge of accessing PMNM, and the complexity of global change issues. There are few existing studies of climate change impacts or projections for the NWHI, and the area's unique characteristics limit the efficacy of extrapolating knowledge from other places. The time and expense of accessing remote PMNM is a second barrier to the $\mathrm{C}_{2} \mathrm{AP}$ 's credibility, because it limits the information and experiences that underpin the $\mathrm{C}_{2}$ AP's findings.

\section{DISCUSSION}

We implemented a case-study approach to explore the nature, sources, and influence of coproductive capacity, a concept proposed by van Kerkhoff and Lebel (2015). Specifically, we explored the three questions identified in our introduction about the relative influence of different sources of coproductive capacity, and the role of knowledge integration as it relates to coproduction outcomes. To investigate these questions, we analyzed the characteristics and sources of coproductive capacity involved in: (1) establishing the salience, legitimacy, and credibility of a boundary object; and (2) determining the extent to which different knowledge systems were integrated within the boundary object. 
Table 2. Ways the three coproductive capacities (rows) contributed to establishing the $\mathrm{C}_{2} \mathrm{AP}$ 's salience, legitimacy, and credibility, and ways they supported the integration of Native Hawaiian and Western scientific knowledge.

\begin{tabular}{|c|c|c|c|}
\hline \multicolumn{4}{|l|}{$\begin{array}{r}\text { Coproductive Capacities } \\
\mathrm{A}\end{array}$} \\
\hline Salient & Legitimate & Credible & Integrated Knowledge \\
\hline \multicolumn{4}{|l|}{ Individual and Organizational Capabilities } \\
\hline & $\begin{array}{l}\text { - Leadership by PMNM's } \\
\text { comanagers in initiating and } \\
\text { implementing the coproduction } \\
\text { process. }\end{array}$ & $\begin{array}{l}\text { - A long-enduring cultural } \\
\text { connection and resurgent } \\
\text { traditional ecological knowledge } \\
\text { about PMNM among Native } \\
\text { Hawaiians. } \\
\text { - Experienced and established } \\
\text { capacity for strong science within } \\
\text { the Northwestern Hawaiian } \\
\text { Islands (NWHI). }\end{array}$ & $\begin{array}{l}\text { - Individuals who belong to } \\
\text { multiple stakeholder groups (e.g., } \\
\text { Native Hawaiian scientists). }\end{array}$ \\
\hline $\begin{array}{l}\text { Social-Ecological Context } \\
\text { • Recognition of PMNM as a } \\
\text { special place, both a national } \\
\text { monument and a world heritage } \\
\text { site for nature and culture. } \\
\text { • Presence of policy mandates and } \\
\text { science funding aimed at } \\
\text { catalyzing climate change } \\
\text { adaptation. }\end{array}$ & \multicolumn{2}{|l|}{$\begin{array}{l}\text { - PMNM's existing comanagement } \\
\text { structure and its formally } \\
\text { recognized authority to develop } \\
\text { the } \mathrm{C}_{2} \mathrm{AP} \text {. }\end{array}$} & $\begin{array}{l}\text { - History of collaboration among } \\
\text { many participants. }\end{array}$ \\
\hline $\begin{array}{l}\text { Knowledge Coproduction Process } \\
\text { - The coproduction focus on } \\
\text { global climate change was viewed } \\
\text { as addressing a significant threat } \\
\text { to PMNM. }\end{array}$ & $\begin{array}{l}\text { - Oriented around consensus } \\
\text { decision making, as well as } \\
\text { synthesizing the best available } \\
\text { knowledge through a mutual } \\
\text { learning process. } \\
\text { - Explicitly considered } \\
\text { representation and transparency. }\end{array}$ & $\begin{array}{l}\text { - Incorporated capacity building } \\
\text { strategies. }\end{array}$ & $\begin{array}{l}\text { - Used teams of Native Hawaiian } \\
\text { and Western scientists/managers to } \\
\text { cofacilitate working groups at two } \\
\text { workshops. } \\
\text { - Facilitated as an iterative process } \\
\text { over a two-year timeframe. }\end{array}$ \\
\hline
\end{tabular}

\section{Nature, sources, and influence of coproductive capacities}

Our analysis identified how different sources of coproductive capacity contributed to producing key attributes of influential knowledge (Table 2). Individual and organizational capacities ( $\mathrm{C} 1$, Fig. 1) were most influential in establishing the boundary object's credibility, the broader SES (C2) was most influential in establishing its salience, and the coproduction process (C3) was the dominant influence in establishing the $\mathrm{C}_{2}$ AP's legitimacy. All three sources of coproductive capacity had at least some influence in each area. Although these results are intuitively logical, further research is needed to determine their generalizability to other situations.

\section{Interplay of coproductive capacities and knowledge integration} In crafting the coproduction process, some of PMNM's comanagers intended to deeply integrate the knowledge and values of all three actor groups. The goal of integration was viewed as a step beyond the side-by-side presentation of divergent stakeholder views in other monument documents, such as its permitting regulations (United States Government, 2006a) and its management plan (PMNM 2008b). The belief among some comanagers was that developing the $\mathrm{C}_{2} \mathrm{AP}$ provided an opportunity to build on supportive elements of PMNM's foundation, including its recent world heritage designation and history of collaborative engagement. They sought to integrate stakeholder knowledge into a transformational, unified understanding of climate change impacts and responsive options. In designing the coproduction process, a great deal of attention was given to creating the conditions that could achieve this knowledge integration (Fig. 2).

The final draft $\mathrm{C}_{2} \mathrm{AP}$ fulfills this intention for integration through some of its guiding principles and some of the research and management actions it proposes. For example, its fourth draft management principle offers a dynamic vision for management that draws on understandings from both traditional knowledge and ecology. This approach is a departure from Western management approaches, which aim to maintain ecosystems in a more static, pristine state, an approach which is untenable within the context of climate change (Kareiva et al. 2008).

Overall, however, the $\mathrm{C}_{2} \mathrm{AP}$ continues the side-by-side presentation of different stakeholder views, rather than offering an integrated understanding. This result raises questions about the importance of knowledge integration within coproduction and whether there is a tension between achieving integration and achieving salience, legitimacy, and credibility in developing boundary objects. Given that we believe the $\mathrm{C}_{2} \mathrm{AP}$ is perceived as salient, legitimate, and credible by the three actor groups, does this lack of integration represent a shortcoming in the coproduction process because integration is central to 
coproduction? Or, given the project's focus on climate change and existing characteristics of the broader SES, was it necessary to limit integration to establish the $\mathrm{C}_{2} \mathrm{AP}$ as salient, legitimate, and credible by the scientists and Native Hawaiians involved in the process?

To help answer these questions, we further discuss the barriers to integration identified in Table 1. Our experience exemplified four barriers to knowledge integration that are described in the literature:

1. Asymmetrical priorities and capabilities: A number of authors have noted that the foci of scientific and traditional knowledge tend to be different and often complementary (Moller et al. 2004, Bohensky and Maru 2011). In our case, the $\mathrm{C}_{2} \mathrm{AP}$ is a comprehensive document and some topics did not lend themselves to knowledge integration. For example, although most actor groups were interested in the results of modeled projections about sea-level rise or changes in precipitation, there was no comparable knowledge system to easily integrate into this science-based perspective; Native Hawaiian participants had little appetite for extrapolating traditional knowledge to answer temporally distant questions. There is the potential to create integrated knowledge about features that are important to Native Hawaiian culture, such as climate change impacts to coral reefs, which are a cultural keystone species. However, questions about the overall impact of climate change on Native Hawaiian culture can only comfortably be answered by those who have a nuanced and embodied understanding of the culture and how it evolves in response to a variety of shocks and pressures. In these cases, forcing knowledge integration where it did not naturally occur was viewed as potentially detrimental to the $\mathrm{C}_{2}$ AP's credibility. Limiting the scope of the $\mathrm{C}_{2} \mathrm{AP}$ to only those areas that lent themselves to integration would have compromised the document's salience. These decisions are consistent with the broader literature on knowledge integration, which notes that integration taken for its own sake, when there is no clear benefit to the exercise, risks becoming tokenistic or superficial (Huntington 2000).

2. Distinct ontologies: For some of the topics examined in developing the $\mathrm{C}_{2} \mathrm{AP}$, there was a clear opportunity and benefit to integrating scientific and traditional knowledge. These opportunities were largely focused around understanding the status, projected changes, and management opportunities related to marine and terrestrial species and habitats. The barrier to integration in this instance was the difficulty in bringing these knowledge systems together in a fair, genuine, and rigorous way. Specifically, in finding a way that did not give preference to one knowledge system over the other, and truly resulted in a new and transformational understanding. The challenge in achieving this type of transformative integration is widely recognized in the literature. In their investigation of knowledge integration through a volume of case studies, Berkes et al. (2006:319) observed, "If one point of agreement exists among the authors, it is that bridging knowledge systems is not easy. However, most agree that it is nonetheless important and necessary." At the root of this difficulty are inherent issues of power disparity and fundamental differences in ontologies and methodological approaches to understanding the world, which challenge communication and integration (Bohensky and Maru 2011). Within the $\mathrm{C}_{2} \mathrm{AP}$, we responded to these challenges by identifying relevant focal areas for future transdisciplinary research that can be conducted in a slower, more focused, and experiential way. Future work should consider drawing on the strategies for knowledge integration that are identified by Berkes et al. (2004) and Bohensky and Maru (2011).

3. Power imbalances: The influence of power dynamics on the appropriateness and form of knowledge integration is perhaps the most widely discussed issue in this literature (e.g., see Agrawal 1995, Berkes et al. 2006, Bohensky and Maru 2011). Throughout this coproduction process, a concerted effort was made to ensure each actor group was given an equal voice in developing the $\mathrm{C}_{2} \mathrm{AP}$. However, the equity offered within the confines of the coproduction project did not change the situation that the $\mathrm{C}_{2} \mathrm{AP}$ will be implemented within a system whose formal institutions continue to privilege Western science and management (see Results, subsection on legitimacy). We observed that this disparity served as a disincentive to integration, and some actors appeared to feel the $\mathrm{C}_{2} \mathrm{AP}$ had greater legitimacy when certain views were articulated clearly and separately. A similar reticence was observed by Armitage et al. (2012:251), whose studies in Canada's Arctic found that building integrated perspectives required several decades, "an enabling policy environment (i.e., comprehensive land claims agreements and legal requirement to consider traditional knowledge), and longer term research partnerships between scientists and resource users."

4. Leadership attrition: The idea of more fully integrating traditional and scientific knowledge within the $\mathrm{C}_{2} \mathrm{AP}$ was originally championed by two of PMNM's comanagers. Over the two-year duration of the project, both of these champions had changes in their employment, which removed them from the coproduction steering committee halfway through the process. Although the project continued to be implemented using principles that created space for knowledge integration, the absence of dedicated advocates for this outcome meant there was little counter weight to the integration barriers described above. The importance of leadership and participant continuity for achieving different coproduction outcomes is echoed in the literature (Blackstock et al. 2007, Lang et al. 2012).

Our experience suggests that different knowledge types should be integrated when it is useful for creating influential knowledge. Whether integration is a support or a barrier to producing a boundary object that is perceived as salient, legitimate, and credible, depends on: the specific topic or focus of the coproduction project (C3, Fig. 1), the power dynamics of the broader SES (C2), and the interests and capabilities of the project's constituents $(\mathrm{C} 1)$. Coercing or forcing knowledge integration in a way that is insensitive to these issues may compromise the influence of the resulting knowledge or boundary object. We view the coproduction process as an opportunity to facilitate a shared conversation around the value 
of knowledge integration. If integration is viewed as unhelpful because different knowledge types naturally complement, rather than overlap each other, then separate presentations of the knowledge may best support perceptions of a boundary object's salience. Where lack of integration stems from power inequities in the broader SES, the stakeholders involved in coproduction must decide whether integrated knowledge would be viewed as legitimate and credible by the broader communities they represent. In these circumstances, it may be most skillful to use the coproduction process as a way to illuminate governance changes needed in the broader SES (F1, Fig. 1), but to maintain a separate presentation of knowledge systems. In summary, integration is not the only way to reconcile different stakeholder views toward creating an influential boundary object. The extent to which knowledge integration is helpful is determined by characteristics of all three sources of coproductive capacity.

\section{CONCLUSIONS}

We have proposed and applied a conceptual framework for knowledge coproduction and coproductive capacities. The framework: (1) articulates a hypothesized theory of change by which coproduction can help solve sustainability problems; (2) offers a structure for systematically investigating the capacities, mechanisms, and dynamics of knowledge coproduction; and (3) provides a guide for practitioners who are designing coproduction processes. Our initial application found that all three coproductive capacities contribute toward the level of influence exerted by coproduced knowledge. We found that the boundary object's salience was most influenced by the broader SES (Fig. 1, C2), its legitimacy through the coproduction process (C3), and its credibility by the capacities of the individuals involved (C1). Additionally, our analysis supports our decision to identify 'transformational learning' as an immediate outcome of coproduction $(\mathrm{O} 1)$, rather than specifying transformational or integrated knowledge. We suggest that coproduction must shift stakeholder perceptions from narrow, self-focused views toward a collective understanding of a sustainability problem. This shift can include creating integrated knowledge if this process does not compromise the legitimacy of the resulting boundary object. Overall, we found that coproduction processes cannot necessarily eliminate the negative effects that entrenched power disparities have on collaborative responses to complex issues. Importantly however, a reflective coproduction process can illuminate the types of institutional changes needed to enable wise and fair responses to sustainability problems (Fig. 1, feedback 1).

Responses to this article can be read online at: http://www.ecologyandsociety.org/issues/responses. $\mathrm{php} / 7038$

\section{Acknowledgments:}

We thank Lorrae van Kerkhoff, Dan Polhemus, Beth Flint, Kelly Gleason, Jean Kenyon, Jeff Maynard, Stephen Miller, Rod Salm, Daniel Wagner, and two anonymous reviewers for comments on earlier versions of this manuscript. We are also grateful to Deanna Spooner, Sam Gon, Rusty Brainard, and Aulani Wilhelm for helpful insights while facilitating development of the $C_{2} \mathrm{AP}$. We thank
PMNM for inviting us to work with the Monument on this project. The views and opinions expressed in this article are those of the authors and do not necessarily reflect the opinions, official policy, or position of any agency of the U.S. Government, the Polynesian Voyaging Society, or of any other persons or organizations involved in the $\mathrm{C}_{2} \mathrm{AP}$ coproduction process.

\section{LITERATURE CITED}

Agrawal, A. 1995. Dismantling the divide between Indigenous and scientific knowledge. Development and Change 26:413-439. http://dx.doi.org/10.1111/j.1467-7660.1995.tb00560.x

Armitage, D., R. de Loö, and R. Plummer. 2012. Environmental governance and its implications for conservation practice. Conservation Letters 5:245-255. http://dx.doi.org/10.1111/ j.1755-263X.2012.00238.X

Berkes, F., W. V. Reid, T. J. Wilbanks, and D. Capistrano. 2006. Bridging scales and knowledge systems. Pages 315-331 in W. V. Reid, F. Berkes, T. J. Wilbanks, and D. Capistrano, editors. Bridging scales and knowledge systems: concepts and applications in ecosystem assessment. Island, Washington, D.C., USA.

Blackstock, K. L., G. J. Kelly, and B. L. Horsey. 2007. Developing and applying a framework to evaluate participatory research for sustainability. Ecological Economics 60:726-742. http://dx.doi. org/10.1016/j.ecolecon.2006.05.014

Bohensky, E. L., and Y. Maru. 2011. Indigenous knowledge, science, and resilience: what have we learned from a decade of international literature on "integration"? Ecology and Society 16 (4): 6. http://dx.doi.org/10.5751/ES-04342-160406

Bremer, S., and B. Glavovic. 2013. Mobilizing knowledge for coastal governance: re-framing the science-policy interface for integrated coastal management. Coastal Management 41:39-56. http://dx.doi.org/10.1080/08920753.2012.749751

Cash, D. W., W. C. Clark, F. Alcock, N. M. Dickson, N. Eckley, D. H. Guston, J. Jager, and R. B. Mitchell. 2003. Knowledge systems for sustainable development. Proceedings of the National Academy of Sciences 100:8086-8091. http://dx.doi.org/10.1073/ pnas. 1231332100

Christie, P. 2011. Creating space for interdisciplinary marine and coastal research: five dilemmas and suggested resolutions. Environmental Conservation 38:172-186. http://dx.doi.org/10.1017/ $\underline{\mathrm{S} 0376892911000129}$

Crona, B. I., and J. N. Parker. 2012. Learning in support of governance: theories, methods, and a framework to assess how bridging organizations contribute to adaptive resource governance. Ecology and Society 17(1): 32. http://dx.doi. org/10.5751/ES-04534-170132

DeMartini, E. E., and A. M. Friedlander. 2004. Spatial patterns of endemism in shallow-water reef fish populations of the Northwestern Hawaiian Islands. Marine Ecology-Progress Series 271:281-296. http://dx.doi.org/10.3354/meps271281

Emory, K. P. 2002. Archaeology of Nihoa and Necker islands. 2nd edition. Bishop Museum Press, Honolulu, Hawaii, USA.

Friedlander, A. M., and E. E. DeMartini. 2002. Contrasts in density, size, and biomass of reef fishes between the Northwestern 
and main Hawaiian islands: the effects of fishing down apex predators. Marine Ecology Progress Series 230:253-264. http://dx. doi.org/10.3354/meps230253

Friedlander, A. M., K. Keller, L. Wedding, A. Clarke, and M. Monaco. 2009. A marine biogeographic assessment of the Northwestern Hawaiian Islands. National Ocean and Atmospheric Administration (NOAA) Technical Memorandum National Ocean Service (NOS) National Centre for Coastal Oceans Science (NCCOS) 84, Silver Spring, Maryland, USA. [online] URL: http://ccma.nos.noaa.gov/ecosystems/sanctuaries/ nwhi/

Future Earth transition team. 2012. Future Earth initial design. http://www.icsu.org/future-earth/media-centre/relevant_publications/ future-earth-initial-design-report.

Glaser, M., G. Krause, B. M. W. Ratter, and M. Welp, editors. 2012. Human-nature interaction in the Anthropocene: potentials of social-ecological systems analysis. Routledge, Oxon, UK.

Grigg, R. W. 2006. The history of marine research in the Northwestern Hawaiian Islands: lessons from the past and hopes for the future. Atoll Research Bulletin 543:13-22.

Hansen, L., J. Hoffman, C. Drews, and E. Mielbrecht. 2010. Designing climate-smart conservation: guidance and case studies. Conservation Biology 24:63-69. http://dx.doi.org/10.1111/ j.1523-1739.2009.01404.x

Holm, P., M. E. Goodsite, S. Cloetingh, M. Agnoletti, B. Moldan, D. J. Lang, R. Leemans, J. O. Moeller, M. P. Buendı'a, W. Pohl, R. W. Scholz, A. Sors, B. Vanheusdenm, K. Yusoff, and R. Zondervan. 2012. Collaboration between the natural, social and human sciences in global change research. Environmental Science and Policy.

Huntington, H. P. 2000. Using traditional ecological knowledge in science: methods and applications. Ecological Applications 10:1270-1274. http://dx.doi.org/10.1890/1051-0761(2000)010[1270: UTEKIS]2.0.CO;2

Kame'eleihiwa, L. 2009. Hawai' i-nui-akea cousins: ancestral gods and bodies of knowledge are treasures for the descendants. Te Kaharoa 2:42-63. [online] URL: http://www.tekaharoa.com/ index.php/tekaharoa/article/view/43/15

Kareiva, P., C. Enquist, A. Johnson, S. H. Julius, J. Lawler, B. Petersen, L. Pitelka, R. Shaw, and J. M. West. 2008. Synthesis and conclusions. Pages 319-359 in S. H. Julius and J. M. West, editors. Preliminary review of adaptation options for climate-sensitive ecosystems and resources. U.S. Climate Change Science Program, Washington, D.C., USA. [online] URL: http://cfpub.epa.gov/ ncea/cfm/recordisplay.cfm?deid $=180143$

Kittinger, J. N., A. Dowling, A. R. Purves, N. A. Milne, and P. Olsson. 2011. Marine protected areas, multiple-agency management, and monumental surprise in the Northwestern Hawaiian Islands. Journal of Marine Biology 17. http://dx.doi. org/10.1155/2011/241374

Lang, D. J., A. Wiek, M. Bergmann, M. Stauffacher, P. Martens, P. Moll, M. Swilling, and C. J. Thomas. 2012. Transdisciplinary research in sustainability science: practice, principles, and challenges. Sustainability Science 7:25-43. http://dx.doi. org/10.1007/s11625-011-0149-x
Lemos, M. C., and B. J. Morehouse. 2005. The co-production of science and policy in integrated climate assessments. Global Environmental Change 15:57-68. http://dx.doi.org/10.1016/j. gloenvcha.2004.09.004

Mauser, W., G. Klepper, M. Rice, B. S. Schmalzbauer, H. Hackmann, R. Leemans, and H. Moore. 2013. Transdisciplinary global change research: the co-creation of knowledge for sustainability. Current Opinion in Environmental Sustainability 5:420-431. http://dx.doi.org/10.1016/j.cosust.2013.07.001

Mitchell, R. B., W. C. Clark, and D. W. Cash. 2006. Information and influence. Pages 307-338 in R. B. Mitchell, W. C. Clark, D. W. Cash, and N. M. Dickson, editors. Global environmental assessments: information and influence. MIT Press, Cambridge, Massachusetts, USA.

Moller, H., F. Berkes, P. O. Lyver, and M. Kislalioglu. 2004. Combining science and traditional ecological knowledge: monitoring populations for co-management. Ecology and Society 9(3): 2. [online] URL: http://www.ecologyandsociety.org/vol9/ iss $3 / \operatorname{art} 2 /$

National Oceanic and Atmospheric Administration (NOAA). 2010. NOAA's climate-smart sanctuaries: helping the National Marine Sanctuary System address climate change. Office of National Marine Sanctuaries, National Oceanic and Atmospheric Administration, Silver Spring, Maryland, USA. [online] URL: http://sanctuaries.noaa.gov/management/climate/ pdfs/css.pdf

Pahl-Wostl, C., C. Giupponi, K. Richards, C. Binder, A. de Sherbinin, D. Sprinz, T. Toonen, and C. van Bers. 2012. Transition towards a new global change science: requirements for methodologies, methods, data and knowledge. Environmental Science and Policy. http://dx.doi.org/10.1016/j.envsci.2012.11.009

Papahānaumokuākea Marine National Monument (PMNM). 2008a. Nomination of Papahānaumokuākea Marine National Monument for inscription on the world heritage list. Papahānaumokuākea Marine National Monument, Honolulu, Hawaii, USA. [online] http://www.papahanaumokuakea.gov/ management/worldheritage.html

Papahānaumokuākea Marine National Monument (PMNM). 2008b. Papahānaumokuākea Marine National Monument management plan. Page 372. Papahānaumokuākea Marine National Monument, Honolulu, Hawaii, USA. [online] URL: http://www.papahanaumokuakea.gov/management/mp.html

Papahānaumokuākea Marine National Monument (PMNM). 2011. Maritime heritage research, education, and management plan: Papahānaumokuākea Marine National Monument. Papahānaumokuākea Marine National Monument, Honolulu, Hawaii, USA. [online] URL: http://www.papahanaumokuakea. gov/maritime/

Peters, G. P., R. M. Andrew, T. Boden, J. G. Canadell, P. Ciais, C. Le Quéré, G. Marland, M. R. Raupach, and C. Wilson. 2013. The challenge to keep global warming below $2{ }^{\circ} \mathrm{C}$. Nature Climate Change 3:4-6. http://dx.doi.org/10.1038/nclimate1783

Pohl, C. 2008. From science to policy through transdisciplinary research. Environmental Science and Policy 11:46-53. http://dx. doi.org/10.1016/j.envsci.2007.06.001 
Pretty, J. 2011. Interdisciplinary progress in approaches to address social-ecological and ecocultural systems. Environmental Conservation 38:127-139. http://dx.doi.org/10.1017/S0376892910000937

Rauzon, M. J. 2001. Isles of refuge: wildlife and history of the Northwestern Hawaiian Islands. University of Hawaii Press, Honolulu, Hawaii, USA.

Selkoe, K. A., B. S. Halpern, C. M. Ebert, E. C. Franklin, E. R. Selig, K. S. Casey, J. F. Bruno, and R. J. Toonen. 2009. A map of human impacts to a "pristine" coral reef ecosystem, the Papahānaumokuākea Marine National Monument. Coral Reefs 28:635-650. http://dx.doi.org/10.1007/s00338-009-0490-Z

Selkoe, K. A., B. S. Halpern, and R. J. Toonen. 2008. Evaluating anthropogenic threats to the Northwestern Hawaiian Islands. Aquatic Conservation-Marine and Freshwater Ecosystems 18:1149-1165. http://dx.doi.org/10.1002/aqc.961

Shallenberger, R. J. 2006. History of management in the Northwestern Hawaiian Islands. Atoll Research Bulletin 543:23-31. [online] URL: http://www.denix.osd.mil/nr/crid/ Coral_Reef_Iniative_Database/NW_Hawaiian_Islands_files/Shallenberger, $\% 202007$.pdf

Stone, D. A. 2002. Policy paradox: the art of political decision making. Revised edition. W.W. Norton and Company, New York, New York, USA.

United Nations Development Programme (UNDP). 1998. Capacity assessment and development in a systems and strategic management context. United Nations Development Programme, New York, New York, USA. http://www.cbd.int/doc/pa/tools/ Capacity $\% 20$ assessment $\% 20$ and $\% 20$ development.pdf

United States Government. 1972, as amended. Marine mammal protection act. U.S. Government, National Oceanic and Atmospheric Administration, Silver Springs, Maryland, USA. [online] URL: http://www.nmfs.noaa.gov/pr/laws/mmpa/text. $\underline{\mathrm{htm}}$

United States Government. 1973, as amended. Endangered species act. U.S. Government, National Oceanic and Atmospheric Administration, Silver Springs, Maryland, USA. [online] URL: http://www.nmfs.noaa.gov/pr/laws/esa/text.htm

United States Government. 2006a. Northwestern Hawaiian Islands Marine National Monument, permitting procedures and criteria. 50 C.F.R. $\S 404.11$. U.S. Government, Washington, D.C., USA. [online] URL: http://www.law.cornell.edu/cfr/text/50/ part-404

United States Government. 2006b. Proclamation No. 8031, 71 Fed. Reg. 36,443 (June 15, 2006), amended by Proclamation No. 8112, 72 Fed. Reg. 10,031 (Feb.28, 2007). U.S. Government, Washington, D.C., USA.

Van Kerkhoff, L. E., and L. Lebel. 2015. Coproductive capacities: rethinking science-governance relations in a diverse world. Ecology and Society 20(1): 14. http://dx.doi.org/10.5751/ ES-07188-200114
Walter, A. I., S. Helgenberger, A. Wiek, and R. W. Scholz. 2007. Measuring societal effects of transdisciplinary research projects: design and application of an evaluation method. Evaluation and Program Planning 30:325-338. http://dx.doi.org/10.1016/j. evalprogplan.2007.08.002

Weiss, C. H. 1973. Where politics and evaluation meet. Evaluation $1: 37-45$

Weiss, C. H. 1976. Using research in the policy process: potential and constraints. Policy Studies Journal 4:224-228.

White, D. D., A. Wutich, K. L. Larson, P. Gober, T. Lant, and C. Senneville. 2010. Credibility, salience, and legitimacy of boundary objects: water managers' assessment of a simulation model in an immersive decision theater. Science and Public Policy 37:219-232. http://dx.doi.org/10.3152/030234210X497726 